\section{Disability as Psycho-Emotional Disablism: A Theoretical and Philosophical Review of Education Theory and Practice}

David I. Hernandez-Saca ${ }^{1}$ and Mercedes A. Cannon $^{2}$

${ }^{1}$ Arizona State University, Tempe, AZ, USA

${ }^{2}$ Indiana University - Purdue University

Indianapolis, Indianapolis, IN, USA

\section{Synonyms}

Disability Oppression; Psycho-emotional dimensions of disability; Ableism; Disability Studies; Disability Studies in Education

\section{Introduction}

Disability oppression is well documented in the extensive body of literature of disability studies (DS). Common debates include definitional arguments about what counts as disability from purely medical models of disability to social models of disability. The medical models are usually institutionalized within society's major institutions both ideologically (e.g., the problem lies in people's neurology) and materially (e.g., inaccessible buildings and the speed at which lectures are presented by educational agents such as teachers to students with disabilities). The social models are traditionally lauded antithetical to the medical ones that situate disability, and hence disability oppression, originating from the social environment (e.g., social relationships and/or physical environment). From a DS lens, both the medical and social models of disability point to sources of disability oppression, however, to the direct opposite sources. Nevertheless, both the medical and social models, according to the DS scholar Carol Thomas (1999), fail to theorize the psychoemotional aspects of disability oppression.

This entry will summarize the literature on this gap that Thomas (1999) has pointed out as it relates to the educational philosophical and theoretical writings about the psycho-emotional aspects of disability oppression coming from the most recent field of Disability Studies in Education (DSE), an outgrowth of the interdisciplinary field of DS that shares its characteristics. Although DSE scholars' foci are within the field of education, and the related field of inclusive education, both DS and DSE scholars are interdisciplinary in nature at their approach toward their scholarship. Taylor (2006) pointed out "like the area of inquiry on which it is based-Disability Studies-Disability Studies in Education existed before it had a name" (p. xiii). Here Taylor dates the historical intellectual roots of DSE beyond professional and institutional effort to give it such a name, but to the historical-material realities of people living with disabilities that he continued to foreground as being socially constructed in society, "if one prefers, [a] creation" (Taylor

This is the authors' manuscript of the chapter published in its final form as:

Hernandez-Saca, D. I., \& Cannon, M. A. (2016). Disability as Psycho-Emotional Disablism: A Theoretical and Philosophical Review of Education Theory and Practice. 
2006, p. xiii). In other words, "disability" is epistemologically, ontologically, and axiologically a creation of social, historical, and cultural construction. This premise sets the philosophical and theoretical platform that the past, current, and, most likely, future DS and DSE scholars will begin to grapple with the meanings of disability oppression.

Similarly, distinctions between the concepts of disability and impairment are critiqued when the former is usually characterized as a condition resulting from a social construction (i.e., a person becomes disabled by society's views and/or physical structures) and the latter as an "organic" disabling aspect of the body (a part of the body or mind that does not function as typically expected). For example, Shakespeare (2006) asserts that even impairment is a function of judgment, expectations, and arrangements given a sociocultural context of meaning as it relates to the individual and the "values and attitudes of the wider society" (p. 35). Some scholars within the DS community, like Shakespeare, reject the distinction between disability and impairment on (a) philosophical grounds to squarely undergird both from a social constructionist perspective and (b) avoid the medical model of impairment as existing within and on the body. Nevertheless, even though the historical roots of DS and DSE are in foregrounding a social constructionist approach to disability or a social model of disability, taking into account the psycho-emotional as it relates to disability has been a tenuous relationship at best (Thomas 1999). Again, said differently, this entry summarizes this tenuous relationship by unpacking the study of disability oppression and its psychoemotional aspects philosophically and theoretically.

Within this entry, both the terms "people with disabilities" and "disabled people" to refer to people with impairments and disabilities are used. Person-first language, such as people with disabilities, has traditionally been associated with the field of special education, and it indicates that they are a person, first, and not the disability per se. The norm within DS, on the other hand, is placing "disability" first, such as "disabled people," to indicate that disability is a social identity and something to be celebrated (Linton 1998), akin to being gay and feeling proud of one's sexual orientation or to being Black and feeling proud of one's racial orientation. Lastly, in this entry, the terms disability, dis/ability, and disability and ability are used interchangeably to signify the socially constructed nature of the term and phenomena of "disability." Disability and ability denote that both are ideologically contested terms and socially and culturally value-laden phenomena.

\section{Disability Studies Versus Disability Studies in Education: A Short Synopsis}

As suggested above, within DS and DSE, given the central assumption of the social models of disability versus the medical models, the psychology and well-being of disabled people have been under-theorized since the disability rights movement (DRM) of the 1970s Civil Rights Movement. While the academic field of DS grew from the inspiration and activism for human rights and dignity for disabled people, DSE is a more recent development that specifically seeks to focus on the educational contexts of students with disabilities from K-16 and beyond.

Both the academic and political activisms coming from DS and DSE adhere to similar tenets:

(a) Claiming to social models of disability as opposed to medical models, where negative ideological (e.g., stereotypes) and physical (e.g., inaccessible architectural environments) material barriers of society are the cause of the "disability," distinct from disabled people's impairments, nevertheless within both DS and DSE, there are scholars who view impairment as a social construction as well.

(b) Values interdisciplinarity in approaches to theory, research, policy, practice, and action about dis/ability.

(c) Honors the voices and experiences of disabled people themselves as epistemologically valid forms of evidence, encourages disabled people to be researchers and/or co-researchers, and has disabled people theorize about 
disability - characteristics that reflect the epitome of the DRM's slogan: "Nothing About Us Without Us" (Charlton 1998).

(d) Documents, critiques, and subverts instances of ableism (Linton 1998), recognizing it as a form of dehumanization and violence that stem from a medical-psychological model of disability that situates the problem within individuals and their neurology.

(e) Acknowledges the experiences of disabled people themselves as part of interlocking systems of oppression with other markers of socially constructed identities such as race, gender, sexual orientation, and class. Also, within DSE, the history and culture of disabled people are seen as an integral part of the school curriculum.

\section{The Psychological Turn Toward Disability Oppression}

Academically and historically, the psychological dimensions of disability oppression have been written within DS, and they have increasingly been included in writings within DSE. However, for DS, due to its focus on the social nature of disability oppression, disabled people's psychological effects have been largely framed as resulting from the social processes that both DS and DSE interrogate. Reeve (2012) speaks to this historical omission:

\footnotetext{
Although early disability writers such as Paul Hunt (1966) documented the impact of stigma and internalized oppression on the psyche of disabled people, these problems have largely remained a difficulty for the individual to manage whilst the disabled people's movement addressed the more material forms of disadvantage such as exclusion from employment, education and the built environment. It was the naming of these personal experiences as psycho-emotional disablism which has allowed for a sociological analysis of these aspects of social oppression, rather than leaving them in the hands of psychologists and other professionals 'who would not hesitate to apply the individualistic/personal tragedy model to these issues'. (Thomas 1999, p. 74; Reeve 2012, p. 78)
}

In her 1999 book, Female Forms, Carol Thomas introduced the concept of psychoemotional disablism. However, Thomas (1999) was inspired by Tom Shakespeare's observation that "few have raised the issue of individual psychology" within DS (1996, p. 103, as cited in Thomas 1999). The term that was usually used before psycho-emotional disablism was "psychoemotional dimensions of disability," designed "to make connections with other forms of social oppression such as hetero/sexism, ageism, and racism" (Reeve 2012, p. 79). From a feminist perspective, Thomas (1999) critiqued the Union of the Physically Impaired Against Disability's (UPIAS) definition of disability (UPIAS 1976) by seeking to move away from a purely materialist and environmental critique of the phenomena of disability with the crying call of the personal is political. Thomas (1999) foregrounded the psychological aspects of disability oppression or disablism by defining disability as "a form of social oppression involving the social imposition of restrictions of activity on people with impairments and the socially engendered undermining of their psycho-emotional well-being" (p. 3). Thomas undergird the psychological as the fallout of the insidious social processes of disability oppression, acknowledging disability as disablism as being both an individual and structural phenomenon. The structural aspect of disability as disablism regards the environment as the source of disability oppression. The structural aspects of disability as disablism, then, are well identified, documented, and critiqued by adherents to the social model of disability. In other words, Thomas reframes the structural phenomena of disability as disablism as having an impact on the individual psyche and well-being of disabled people. This reframing of disability oppression or disability as disablism that foregrounds the psychological has also been understood as a social relational definition of disability (Reeve 2006).

\section{Accounting for External and Internal Forces for Disability Oppression}

This social relational definition of disability, hence, takes into account the external and the internal aspects of disability oppression (Reeve 2006). Reeves (2006) contends that this 
dialectical relationship of social oppression due to disability has helped illuminate the economic and social disadvantage disabled people confronted. Reeves (2006) reminds us of the feminist tradition that has influenced our understanding of disability oppression and their critique of the social model of disability because it focused on the "public" experiences of oppression as opposed to the more "personal" experiences of oppression. Reeves (2006) underscores that these more "personal" experiences of oppression "operate at the emotional level” (p. 95). Reeves (2006) states: "consequently, an extended social relational definition of disability has been proposed which attempts to address this criticism by explicitly including both barriers 'out there' and those that operate 'in here"” (Reeve 2006, p. 95). The "out there"/public social forces do not exist in isolation to the "in here"/private forces - the personal is political - of disability oppression. A flight of stairs is the environmental mechanism in which a person in a wheelchair is disabled by, while, being stared at or bullied due to one's physical or ability differences "can leave disabled people feeling worthless and ashamed, and may end up preventing them from participating in society as effectively as physically inaccessible environments" or classroom spaces (Reeve 2006, pp. 95-96). Both the "out there" and "in here" dimensions of disability oppression are enveloped by the "cultural representations and disabling images" in society about people with disabilities. The dialectic between the internal and external disabling mechanisms has resulted in internalized oppression by people with disabilities.

\section{Internalized Oppression, Language, and Self: The Case of Labels}

People with disabilities, hence, are not only oppressed by external/“out there"/public social environments and others, but disability oppression includes the internal/“in here"/private dimensions. This latter domain of disability oppression can be understood as internalized oppression. Language, specifically the language of the dominant cultural representations and images of who counts as disabled and what counts as a disability, is one major reason internalized disability oppression exists. From a Marxist historical-materialist perspective, Charlton (1998) writes about the consciousness of disabled people as they experience internalized oppression through their alienation by the hegemonic and dominant worldview of the status quo that "naturalizes superiority and inferiority, power and powerlessness" that he argues characterizes "the internalization of oppression that creates an emasculation of the self" (p. 69). Charlton (1998) continues by defining this latter social process as disabled people incorporating a false consciousness due to their internalized oppression that results in a sense of powerlessness. Incorporating the hegemonic perceptions of institutions, such as the educational system, into one's self-concept or perceptions is an example of the power of labeling and the language of the label to define children and youth as "disabled" (Baglieri and Shapiro 2012). For example, the labeling of children and youth as "emotionally disturbed" or "learning disabled" or any other more "subjective" category within Special Education is a case in point to illustrate the power of labels about disability and their psychoemotional impact on the lived experiences of children and youth labeled. In the next section, we further this discussion and turn to DSE regarding the psycho-emotional aspects of disability oppression through the case study of learning disabilities (LD).

\section{The Psycho-Emotional Oppression of LD Labeling}

According to Vehmas (2012), philosophy has much to teach us about disability and disability oppression. Vehmas (2012) describes philosophy as a tool that investigates the "conceptual boundaries of human thought by means of examples and counter-examples. This means that 'it is done just by asking questions, arguing, trying out ideas and thinking of possible arguments against them, and wondering how our concepts really work" (p. 298). For example, Vehmas (2012) juxtaposes how disability scholars and activists might 
approach disability oppression versus what a philosophical interrogation would be. Vehmas (2012) notes that a philosophical perspective on disability as disablism or disability oppression would ask what count as oppression or disability, "people with disabilities," and what makes them such a group or identify as "disabled" - thus examining the ideas that are taken for granted, philosophy stretches the boundaries of one's understanding of the world. Vehmas (2012) argues that "the basic use of philosophy for disability studies is to question and examine carefully its essential concepts and conceptions, their rational credibility, logical tenability and normative soundness" (Vehmas 2012, pp. 298-299). This philosophical interrogation of disability as disablism is compatible to how DS and DSE scholars have resisted medical-psychological models of disability that reproduce a false consciousness about the nature of disability. Within DS and DSE, scholars have put forward indirect philosophical arguments in deconstructing what counts as ability and disability within society; however, they might not have framed it from a direct and explicit philosophical tradition and perspectives such as what Vehmas (2012) asks us to consider. There are exceptions to this, however, such as the critical special education and DSE scholar Deborah Gallagher.

Historically, the nature of LD has been from a quantitative positivist philosophical worldview, where the traditional field of LD and the dominant master narratives within it, due to its epistemological, ontological, and axiological beliefs, adhere to a medical-psychological model of disability (Gallagher 2007). Nevertheless, there has been a growing body of work from critical special education, DS, and DSE scholars who question the positivist worldview about the nature of $\mathrm{LD}$. For example, these scholars also adhere to pluralistic and interdisciplinary perspectives that interrogate the philosophical underpinnings of not only the nature of LD but also the field of LD and the larger field of Special Education. For example, Ferri et al. (2011) ask the following critical philosophical questions about the academic side of LD: "What is considered acceptable knowledge about learning disabilities? Who decides? What are the origins of this knowledge? Who uses it, and toward what ends? Who, in the end, benefits?" (p. 229). Less so has there been a critique of similar positivist world view and lack of pluralistic methodologies within the subfield and literature of the social and emotional dimensions of LD. This latter literature has found that students with LD have not only academic deficits but also social and emotional ones such as lower selfconcept and suffer from anxiety, depression, suicidal thoughts, and difficulty making friends which leads to loneliness (Bryan et al. 2004). This body of work has documented the social and emotional dimensions of LD, which has contributed to what we know about the nature of the social and emotional aspects of $\mathrm{LD}$, that is, its etiology, its cause, and ontology, its being.

However, just like critical scholars who have critiqued the field of LD for not taking into account culture and sociocultural contexts (Artiles et al. 2011), there is a lack of scholarship as it relates to the social and emotional dimensions of LD from a DS and DSE lens - hence a psychoemotional disablism perspective. For example, these sociocultural contexts include disability, race, ethnicity, gender, social class, immigration status, and language to interrogate the hegemonic norms of white-male middle-class, Englishspeaking, Judeo-Christian, citizen and ablebodied identity group(s). However, the budding field of DSE has begun to produce a body of literature on the practical implications of DSE perspectives about the nature of disability and, hence, disability oppression.

\section{Disrupting Psycho-Emotional Disablism in Schools}

Troublesome Ideologies Within Schooling Policies and Practices. Historically within DSE the dominant ideologies of sociocultural markers of difference as it relates to disability have been critiqued and advocated to be subverted in order to engage in a politics of education and disability that leads toward freedom, liberation, and more inclusive schools and society (Gabel and Connor 2014). For example, from a philosophical and DSE perspective, Gallagher (2006) notes the 
following as it relates to educational debates and what she terms the "natural hierarchy" that undergirds the social construction of sociocultural contexts that schooling policies and practices do not take as the root causes of inequity and injustice in education as it relates to disability and ability difference:

Education debates over tracking/inclusion, testing, and "accountability," curriculum, pedagogy, and so on, are essentially debates over two opposing ideals of what constitutes a "good" society. On the one side are those who view social hierarchy as natural and therefore, if not good, then certainly inevitable. On the opposing side are those who not only see nothing natural about social hierarchy but also view it as inimical to the ideals of social justice and equality. From the latter perspective, the concept of the natural hierarchy has provided the crucial leverage necessary for those in powerful positions to decide through schooling who would be afforded advantages and privileges and who would not. As Brantlinger (2004) cogently points out, "in our present educational and economic ranking systems, some have to be subnormal for the seemingly desirable hierarchies to survive" (p. 491). The concept of natural is important because...its power stems in large measure from the authority of science, which, in turn, derives its power from epistemic assumptions immersed so deeply into western culture that the questioning of them strikes many people as either benignly delusional or overly inflammatory. Thus, the idea of a natural hierarchy is situated at the gravitational center of debates in education and special education, serving as an invisible hand that defends, exonerates, and affirms social/educational inequality. (pp. 65-66)

Gallagher (2006) exposes the common sense of the "natural hierarchy" by firmly placing it in the epistemological matrix within schooling and education that marginalizes and excludes any difference from the norms within schools and society. These ideological exclusions, as Gallagher (2006) notes, often times go unquestioned or untroubled. As framed by Ferri (2006), DSE is about teaching to trouble (p. 303), that is, teaching to trouble the common sense assumptions as it relates to the dominant representations, images, and policies and practices in both school and society about disabled people and students. These former assumptions are institutionalized by the direct opposite epistemological, ontological, and axiological assumptions and tenets that undergird both DS and DSE (see "Disability Studies Versus Disability Studies in Education: A Short Synopsis" section for those tenets). In addition to troubling the historical and ongoing paradigms within schooling policies and practices as it relates to education debates, there is a growing literature and mobilization as it relates to the tenuous relationship between disability, psychology, and the psycho-emotional aspects of disablism or what Dan Goodley and his colleagues also write as disablement (e.g., Goodley and Lawthom 2006).

Toward a Psycho-Emotional Inclusive Praxis. Disability can no longer be considered in isolation from the psycho-emotional aspects of disability oppression. Structural, hegemonic forces in society and schooling, directly and indirectly, influence how individuals and students with disabilities, such as students with LD, experience disablement. In turn, the relationship they have with their disability and how they might conceptualize their "disability identity" or not does not exist in isolation from how they make sense of the macro circulating narratives about what counts as disability.

Inside and outside of the DS and DSE literature, there are narrative and discursive-based approaches toward addressing the psychoemotional dimensions that persons with disabilities, such as students with LD, have experienced and suffer from (e.g., Lambie and Milsom 2010). Further, Goodley and Lawthom (2006) call for an alliance between DS and psychology through the following 11 objectives: (a) rethink impairment, (b) recognize and resist the exclusive psychological elements of disablement, (c) promote socially valued understanding of disabled identities, (d) assume an active/activist vision of people with disabilities, (e) acknowledge the complex relationship between individual and social worlds, (f) work toward enabling psychological practices, (g) transform institutions, (h) promote a psychology of inclusion, (i) critique therapeutic assumptions, (j) seek radical psychological theories, and (k) develop emancipatory research practices (see Goodley and Lawthom (2006) for an extended discussion on each objective). Overall, taking a DS and DSE lens and honoring the local contexts 
of people as they enact their agency on the ground - within their cultural-historical conditions - and using what Artiles (2011) has called an interdisciplinary prism to addressing the intersectional nature of disabled people's multidimensional identity markers and their psycho-emotional disablism can enable a praxis, the coupling of reflection and action, by all stakeholders, disabled people, and students with disabilities toward deconstructing disability as psycho-emotional disablism for liberation, freedom, and social justice.

\section{References}

Artiles, A. J. (2011). Toward an interdisciplinary understanding of educational equity and difference: The case of the racialization of ability. Educational Researcher, 40(9), 431-445.

Artiles, A. J., King-Thorius, K., Bal, A., Waitoller, F., Neal, R., \& Hernandez-Saca, D. I. (2011). Beyond culture as group traits: Future learning disabilities ontology, epistemology, and research knowledge use. Learning Disability Quarterly, 34, 167-179.

Baglieri, S., \& Shapiro, A. (2012). Disability studies and the inclusive classroom: Critical practices for creating least restrictive attitudes. New York: Routledge.

Brantlinger, E. (2004). Confounding the needs and confronting the norms: An extension of Reid and Valle's essay. Journal of Learning Disabilities, 36, 490-499.

Bryan, T., Burstein, K., \& Ergul, C. (2004). The socialemotional side of learning disabilities: A science-based presentation of the state of the art. Learning Disability Quarterly, 27(1), 45-51.

Charlton, J. I. (1998). Nothing about us without us: Disability oppression and empowerment. Berkeley: University of California Press.

Ferri, B. A. (2006). Teaching to trouble. In S. Danforth \& S. L. Gabel (Eds.), Vital questions facing disability studies in education (Vol. 2, pp. 289-306). New York: Peter Lang.

Ferri, B. A., Gallagher, D., \& Connor, D. J. (2011). Pluralizing methodologies in the field of LD from "what works" to what matters. Learning Disability Quarterly, 34(3), 222-231.
Gabel, S., \& Connor, D. J. (2014). Teaching and disability. Mahwah: Erlbaum.

Gallagher, D. J. (2006). The natural history undone: Disability studies' contributions to contemporary debates in education. In S. Danforth \& S. L. Gabel (Eds.), Vital questions facing disability studies in education (Vol. 2, pp. 63-75). New York: Peter Lang.

Gallagher, D. J. (2007). Challenging orthodoxy in special education: On longstanding debates and philosophical divides. In L. Florian (Ed.), The SAGE handbook of special education (pp. 515-527). London: Sage.

Goodley, D., \& Lawthom, R. (2006). Disability and psychology: Critical introductions and reflections. New York: Palgrave Macmillan.

Hunt, P. (Ed.) (1996). Stigma: The experience of disability. London: Geoffrey Chapman.

Lambie, G. W., \& Milsom, A. (2010). A narrative approach to supporting students diagnosed with learning disabilities. Journal of Counseling \& Development, 88(2), 196-203.

Linton, S. (1998). Claiming disability: Knowledge and identity. New York: NYU Press.

Reeve, D. (2006). Towards a psychology of disability: The emotional effects of living in a disabling society. In D. Goodley \& Lawthom (Eds.), Disability and psychology: Critical introductions and reflections (pp. 94-107). London: Palgrave.

Reeve, D. (2012). Psycho-emotional disablism: The missing link? In N. Watson, A. Roulstone, \& C. Thomas (Eds.), Routledge handbook of disability studies (pp. 78-93). London: Routledge.

Shakespeare, T. (2006). Disability rights and wrongs. London: Routledge.

Taylor, S. J. (2006). Before it had a name: Exploring the historical roots of disability studies in education. In S. Danforth \& S. L. Gabel (Eds.), Vital questions facing disability studies in education (Vol. 2, pp. xiii-Xxiii). New York: Peter Lang.

Thomas, C. (1999). Female forms: Experiencing and understanding disability. Buckingham: Open University Press.

UPIAS. (1976). Fundamental principles of disability. London: Union of the Physically Impaired Against Segregation/The Disability Alliance.

Vehmas, S. (2012). What can philosophy tell us about disability. In N. Watson, A. Roulstone, C. Thomas, \& MyiLibrary (Eds.), Routledge handbook of disability studies (pp. 298-309). London: Routledge. 